\title{
A Compact, Tri-Band and 9-Shape Reconfigurable Antenna for WiFi, WiMAX and WLAN Applications
}

\author{
Izaz Ali Shah, Shahzeb Hayat, Ihtesham Khan, Imtiaz. Alam, Sadiq Ullah*, Adeel Afridi \\ Department of Telecommunication Engineering, University of Engineering and Technology, Peshawar, Pakistan
}

\begin{abstract}
This paper introduces a novel 9-shaped multiband frequency reconfigurable monopole antenna for wireless applications, using $1.6 \mathrm{~mm}$ thicker FR4 substrate and a truncated metallic ground surface. The designed antenna performs in single and dual frequency modes depending on switching states. The antenna works in a single band (WiMAX at $3.5 \mathrm{GHz}$ ) when the switch is in the OFF state. The dual band frequency mode (Wi-Fi at $2.45 \mathrm{GHz}$ and WLAN at $5.2 \mathrm{GHz}$ ) is obtained when the switch is turned $\mathrm{ON}$. The directivities are: $2.13 \mathrm{dBi}, 2.77 \mathrm{dBi}$ and $3.99 \mathrm{dBi}$ and efficiencies: $86 \%, 93.5 \%$ and $84.4 \%$ are attained at frequencies $2.45 \mathrm{GHz}, 3.5 \mathrm{GHz}$ and $5.2 \mathrm{GHz}$ respectively. The proposed antenna has VSWR< 1.5 for all the three frequencies. The scattering and far-field parameters of the designed antenna are analyzed using computer simulation technology CST 2014. The performance of the proposed antenna is analyzed on the basis of VSWR, efficiency, gain, radiation pattern and return loss.
\end{abstract}

Index Terms: Wi-Fi, WLAN, WiMAX, reconfigurable, monopole, single band, dual band, switches.

(C) 2016 Published by MECS Publisher. Selection and/or peer review under responsibility of the Research Association of Modern Education and Computer Science

\section{Introduction}

With the tremendous advancement in modern communication devices, researchers have paid all their attentions towards multi and wideband antennas. Portable devices which contain different wireless communication standards, such as Wi-Fi, WiMAX, GSM, UMTS and WLAN use specific frequency band which demands multiband antennas [1]. Multi band antennas have the capability to transmit and receive multiple frequency bands with optimum directivity, gain and efficiency [2].The limitation of multi band antenna is that it is tuned for all frequency bands whether they are required or not, thus consume more power. Moderrn devices need antennas having flexibility to tune to the desired frequency band. An example of mutiple antenna system (such as a mobile handset) shown in Fig. 1 [3], uses several antennas for different wireless services such as:

- $\quad$ Global Positioing System (GPS): $1575.42 \mathrm{MHz}$ (L1) and 1227.60 MHz (L2)

- Bluetooth: $2.4 \mathrm{GHz}(\mathrm{BW}=1 \mathrm{MHz} / \mathrm{Channel})$

- Wireless Fidelity (Wi-Fi): $2.4 \mathrm{GHz}\{\mathrm{BW}=40 \mathrm{MHz}(802.11 \mathrm{n})$ and $20 \mathrm{MHz}(802.11 \mathrm{a}$ or $802.11 \mathrm{~g})\}$

- Personal Global System for Mobile Communication (PGSM): $900 \mathrm{MHz}(890-915 \mathrm{MHz})$

- $\quad$ Extended (E) GSM: $900 \mathrm{MHz}(880 \mathrm{MHz}-915 \mathrm{MHz})$

- Fourth Generation (4G)/ Digitlal Cellular Service (DCS)/Personal Communication Services (PCS): $1800 \mathrm{MHz}$ and $2600 \mathrm{MHz}$

\footnotetext{
* Corresponding author. Tel.: 0092937 9230295; fax: 00929379230296

E-mail address: sadiqullah@uetpeshawar.edu.pk
} 


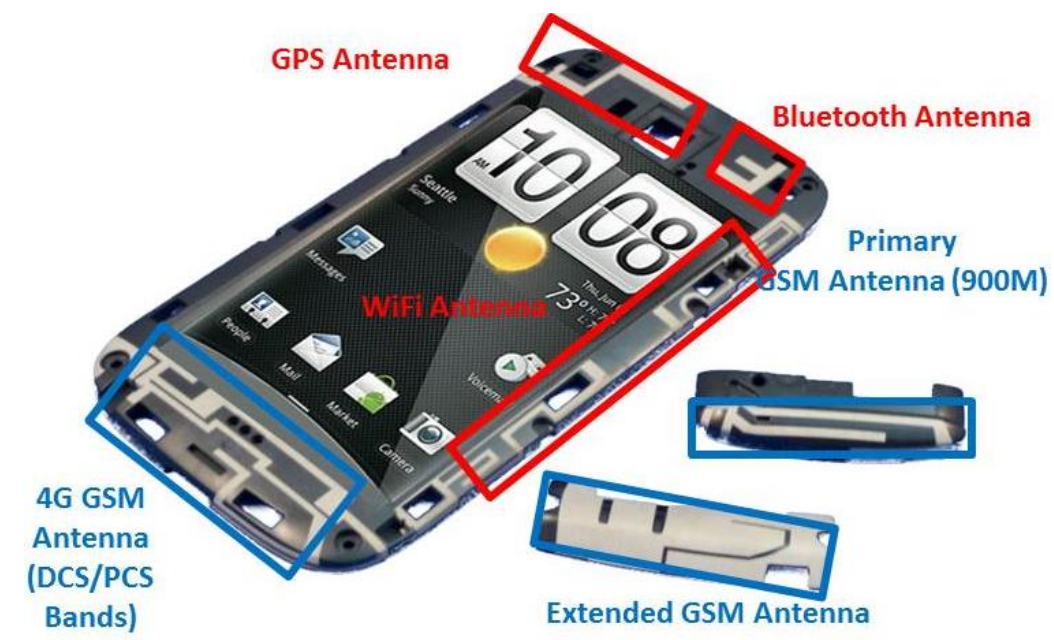

Fig.1. Multi-band, multiple antenna system [3]

Luckily reconfigurable antenna has the ability to cover various frequency ranges. Reconfigurable antennas have the capability to support two or more than two desired wireless services. The reconfigurability can be achieved using various forms of switching circuitry [4]. Recent research show that multi band frequency reconfigurable monopole antenna have brought more attention from researchers because of their attractive feature like compact size, simple integration, easy to fabricate, low cost, optimum efficiency and Omni-directional pattern. Researchers designed different frequency reconfigurable antennas employing different techniques. For Examples Trident shaped [5], G shaped [6], H shaped [7], 7 shaped [8], E shaped [9], Dual Y shaped [10], U shaped [11], C shaped [12], L shaped [13],T shaped [14], F shaped [15] and Triagular shaped [16]. Split ring resonaors and L- shape slots are also used to design multi-band and a nonreconfigurable antenna [17]. By integrating the radiating element with different types of switches (RF-MEMS, lumped elements, varactor diodes and optical switches), the desired resonance frequency can be obtained. Usually the lumped elements are selected due to their high reliability, low cost and require low bias voltage as compared to MEMS switches [18].

In this paper, efficient and compact frequency reconfigurable 9-shape monopole antenna has been designed using an FR4 substrate of thickness $1.6 \mathrm{~mm}$. The propose antenna operates in single mode (WiMAX at $3.5 \mathrm{GHz}$ ) and dual band mode (Wi-Fi at $2.45 \mathrm{GHz}$ and WLAN at $5.2 \mathrm{GHz}$ ). To obtain reconfiguration, lumped elements are used within the radiating element of the designed antenna.

The rest of the research work is organized in the following fashion: Section 2 describes the designing procedure and geometry of 9-shaped monopole antenna. Section 3, discusses simulation results. Section 4 is the conclusion part of the paper.

\section{Antenna Geometry and Theory}

This section presents the basic geometry and design theory of the proposed 9-shape frequency reconfigurable printed antenna. The antenna is reconfigured using a single switch (SW) to obtain dual band $(2.4 \mathrm{GHz}$ and $5.2 \mathrm{GHz}$ ) and single band $(3.5 \mathrm{GHz})$ modes. A truncated metallic ground plane is used for obtaining better radiation efficiency and optimum farfield radiation patterns.

\subsection{Geometry}

The geometry and structural dimensions of the designed 9 shaped monopole antenna for Wi-Fi (2.45 GHz), WiMAX (3.5 $\mathrm{GHz}$ ) and WLAN $(5.2 \mathrm{GHz})$ is depicted in Fig. 2. The 9-shaped radiating element is backed by an FR4 substrate (with relative permittivity 4.5 and tangent loss of 0.019 ) with a truncated metallic ground surface. The FR 4 substrate is easily available at lower costs so it makes the design of the antenna more feasible and affordable. The advantage of truncated ground plane is to attain optimum directivity, good gain and efficiency. The proposed antenna is fed through the $50 \Omega$ micros-trip line with width $(w=3 \mathrm{~mm})$. A waveguide port is assigned to the feed line in order to energize the antenna in the transmitting mode. A slot of $1 \mathrm{~mm}$ width is reserved in the upper part of the vertical arm of the proposed antenna for installing the switch $(S W)$ as shown in Fig. 1. The overall dimension of the designed antenna is $40 \times 35 \times 1.6 \mathrm{~mm}^{3}$. 
Table 1. Outlines the design dimensions of the antenna.
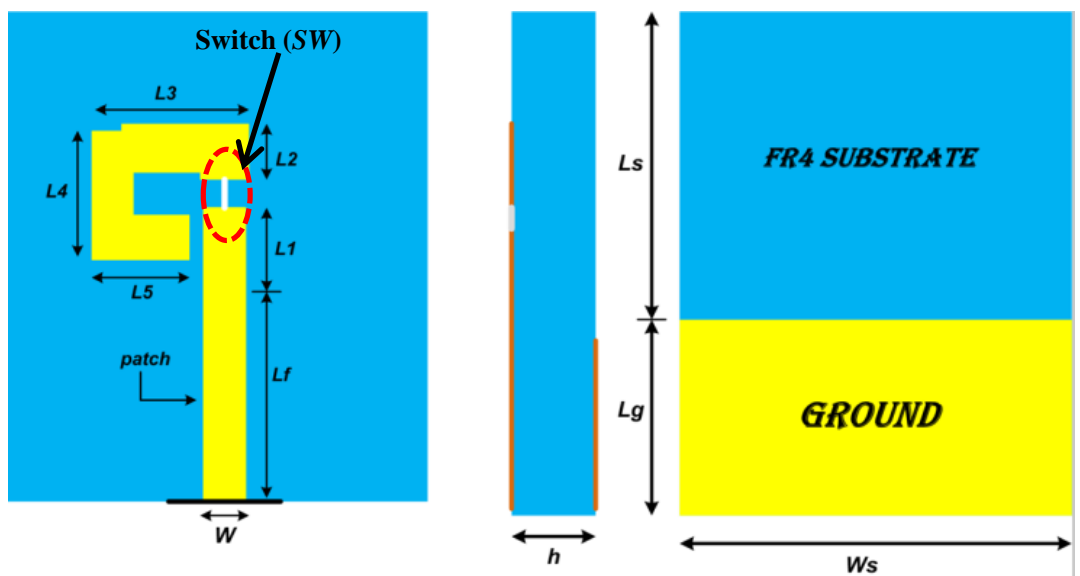

Fig.2. 9 shape reconfigurable monopole antenna (a) Front View (b) Side View (c) Rear View

Table 1. Dimensions of 9 shape antenna

\begin{tabular}{llll}
\hline Lengths & Values(mm) & Lengths & Values(mm) \\
\hline $\boldsymbol{L 1}$ & 7 & $\boldsymbol{L f}$ & 18 \\
$\boldsymbol{L} \mathbf{L}$ & 3 & $\boldsymbol{L} \boldsymbol{s}$ & 40 \\
$\boldsymbol{L 3}$ & 5 & $\boldsymbol{W}$ & 35 \\
$\boldsymbol{L} 4$ & 4 & $\boldsymbol{W}$ & 3 \\
$\boldsymbol{L} 5$ & 6 & $\boldsymbol{h}$ & 1.6 \\
\hline
\end{tabular}

\subsection{Theory}

A $1 \mathrm{~mm}$ wider slot is reserved in order to install the switch $(S W)$ at a proper position in the radiating structure of the proposed antenna. According to the theory of transmission line model [19], the effective resonance lengths of the antenna are computed, i.e. $\mathrm{L}_{2.45}=17.5 \mathrm{~mm}\left(\mathrm{~L}_{1}+\mathrm{L}_{2}+\mathrm{L}_{3} / 2+\mathrm{L}_{4} / 2+\mathrm{L}_{5} / 2+\mathrm{w}\right), \mathrm{L}_{3.5}=10 \mathrm{~mm}\left(\mathrm{~L}_{1}+\mathrm{W}\right)$ and $\mathrm{L}_{5.2}=7.5 \mathrm{~mm}\left(\mathrm{~L}_{3} / 2+\mathrm{L}_{4} / 2+\mathrm{L}_{5} / 2\right)$. Single band (WiMAX at $3.5 \mathrm{GHz}$ ) and dual band (Wi-Fi at $2.45 \mathrm{GHz}$ and WLAN at $5.2 \mathrm{GHz}$ ) frequency mode are obtained by altering state of the switch. The resonant lengths and guided wavelengths are related as:

$$
\begin{aligned}
& L_{2.45}=\lambda_{2.45} / 4 \\
& L_{3.50}=\lambda_{3.50} / 4 \\
& L_{5.20}=\lambda_{5.20} / 4
\end{aligned}
$$

The guided wavelength can be calculated as

$$
\lambda_{f_{r}}=\frac{\mathrm{c}}{f r \sqrt{\varepsilon_{e}}}
$$

Where $f_{r}$ is the resonance frequency is the speed of light and $\varepsilon_{\mathrm{e}}$ is the effective permittivity:

$$
\varepsilon_{e}=\frac{\varepsilon_{r}+1}{2}+\frac{\varepsilon_{r}-1}{2}(1+12 h / w)^{-1 / 2}
$$

Where $\varepsilon_{r}$ is relative permittivity, $h$ is the thickness of the substrate and $W$ is the width of the radiating component in equation (5).

The dimensions of the proposed antenna are optimized for better radiation efficiency $\left(\eta_{\text {rad }}\right)$, which is defined as the ratio of the radiated power $\left(P_{\text {rad }}\right)$ of the antenna to its input power $\left(P_{i n}\right)$.

$$
\eta_{\text {rad }}=\frac{P_{\text {rad }}}{P_{\text {in }}}
$$


The efficiency is higher if the antenna is fed at the right point, resulting in minimum value of reflection coefficient $(\Gamma)$. This factor is the ratio of reflected and incident electric fields. Mathematically it is quantified as:

$$
|\Gamma|=\frac{z_{a n t}-Z_{c}}{z_{a n t}+Z_{c}}
$$

Where, $Z_{a n t}$ is the driving point impedance of the antenna and $Z_{c}$ is the characteristic impedance of the microstrip feed line. Reflection coefficient, voltage standing wave ratio (VSWR) and return loss are interrelated parameters of the antenna, i.e. mathematically:

$$
V S W R=\frac{1+|\Gamma|}{1-|\Gamma|}
$$

If reflection coefficient is small then VSWR approaches unity. The return loss is the ratio of the reflected power $\left(P_{r}\right)$ to the incident power $\left(P_{i n}\right)$ of the antenna and is usually expressed in decibel $(\mathrm{dB})$ scale.

$$
\text { Return Loss }(d B)=\frac{P_{r}}{P_{\text {in }}}=-20 \log _{10}|\Gamma|
$$

Lower value of return loss at the design frequency is achieved if the antenna is properly matched (i.e. low $\Gamma$ ). The gain $(G)$ and directivity $(D)$ of the proposed antenna are related by the radiation efficiency. The gain is usually expressed in decibel $(\mathrm{dB})$ as follows:

$$
G(d B)=10 * \log _{10}\left(\eta_{\text {rad }} D\right)
$$

\section{Results}

To examine the performance of the designed monopole antenna,the radiating components are designed,analyzed and simulated employing CST Micro Wave Studio MWS 2014 [20].

To excite the designed monopole antennna wave guide port is employed. Return loss, scattering parameters, VSWR, impedence, surface electric field, surface current and directivity (in $E$ and $H$ planes) are examined using open add space boundry conditions and transient solver in CST MWS 2014.

When the switch $S W$ is ON,the designed antenna radiate in dual band frequency mode $(2.45 \mathrm{GHz}$ and $5.2 \mathrm{GHz})$ giving return loss of $-15 \mathrm{~dB}$ and $-13.55 \mathrm{~dB}$ respectively, when the switch $\mathrm{SW}$ is turned OFF the 9 shape antenna works in single band mode $(3.5 \mathrm{GHz})$ with return loss of $-27.1 \mathrm{~dB}$ (Fig. 3a). The antenna gives relatively broader $-10 \mathrm{~dB}$ bandwidth in this band, i.e. $13.5 \%, 35.7 \%$ and $9.94 \%$ at 2.4, 3.5 and $5.2 \mathrm{GHz}$ respectively. The switchinh states are listed in Table 2 . The voltage standing wave ratio (VSWR) of the proposed 9 shape antenna is less than 1.5 for all the three frequency bands. VSWR of the antenna is $1.48,1.09$ and 1.49 at $2.45,3.5,5.2 \mathrm{GHz}$, respectively as depicted in Fig. $3 \mathrm{~b}$.

Table 2. Switching states

\begin{tabular}{lll}
\hline S. & SW & Frequency Modes \\
\hline $\mathbf{1}$ & ON & Dual band $2.45 \mathrm{GHz} \& 5.2 \mathrm{GHz}$ \\
$\mathbf{2}$ & OFF & Single band $3.5 \mathrm{GHz}$ \\
\hline
\end{tabular}




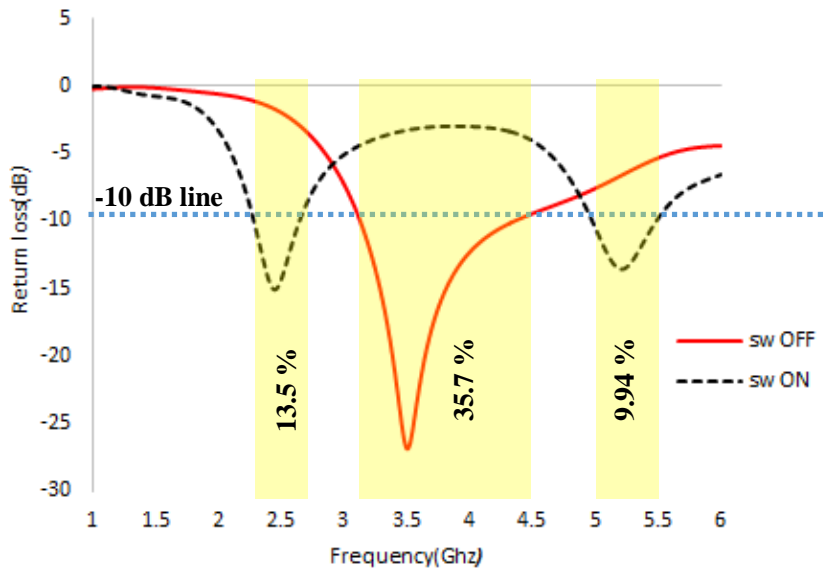

(a)

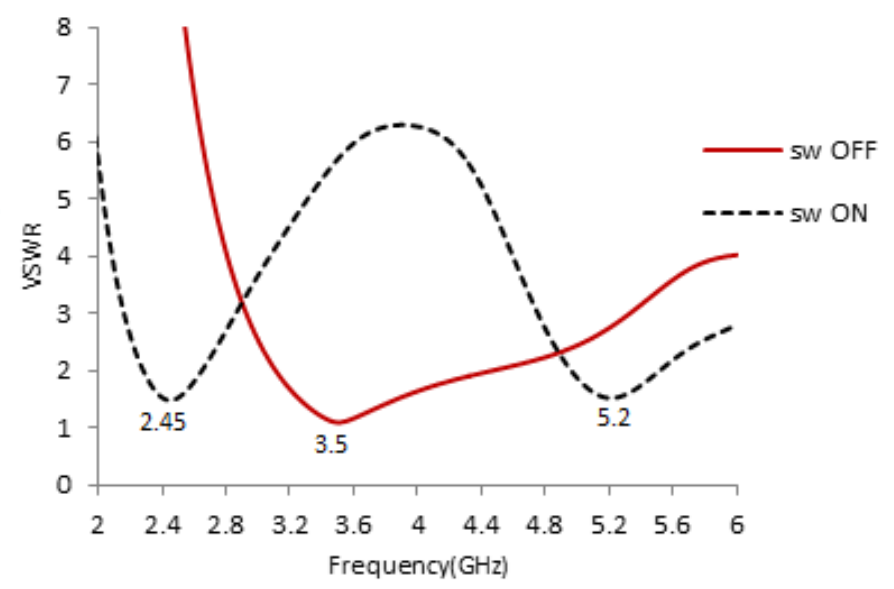

(b)

Fig.3. Scattering parameters of the 9-shape antenna in single and dual band frequency modes (a) Return loss (b) VSWR

Directivity patteren (in the $E$ and $H$ planes) of the monopole antenna at $2.45 \mathrm{GHz}, 3.5 \mathrm{GHz}$ and $5.2 \mathrm{GHz}$ are illustrated in Fig. 4. In single frequency mode the antenna radaites in the far-field with a peak directivity of $2.77 \mathrm{dBi}$. By altering the state of the switch $(\mathrm{SW}=\mathrm{ON})$ the antenna performs in dual frequency mode with directivity values of $2.13 \mathrm{dBi}$ and $3.99 \mathrm{dBi}$ at 2.45 and $5.2 \mathrm{GHz}$, respectively. For further clarity the 3D directivity far-field plots are shown in Fig. 5. The effieciency of the proposed 9 shape monopole antenna is $86 \%$ at $2.45 \mathrm{GHz}, 93.5 \%$ at $3.5 \mathrm{GHz}$ and $84.6 \%$ at $5.2 \mathrm{GHz}$. The corresponding peak absolute gain of the proposed anttenna is $1.48,2.47$ and $3.26 \mathrm{~dB}$ respectively at $2.45,3.5$ and $5.2 \mathrm{GHz}$..

It is worth noticing that the proposed antenna radiates predominently omni-directionally in the H-plane in all the three frequency bands, (WiFi, WLAN and WiMAX) for a given state of the switch. The E-plane radiation pattern is a 'figure of 8 -shape' having a single 'null' appearing at $\theta=90$ degrees for $2.4 \mathrm{GHz}$ and $5.2 \mathrm{GHz}$ frequencies as shown in Fig. $4 \mathrm{a}$ and $\mathrm{b}$ respectively. The position of the 'null' is shifted to $\theta=60$ degrees in the E-plane pattern at $3.5 \mathrm{GHz}$. In this frequency band the shape of the E-plane pattern is nearly omni-directional except the null point.

Summary of the simulation results is outlined in Table 3.

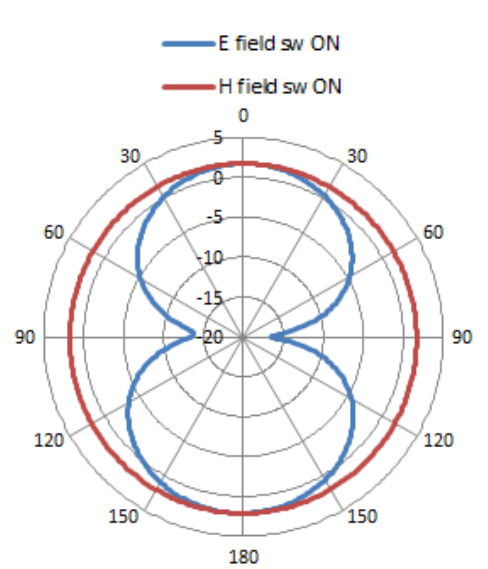

(a)

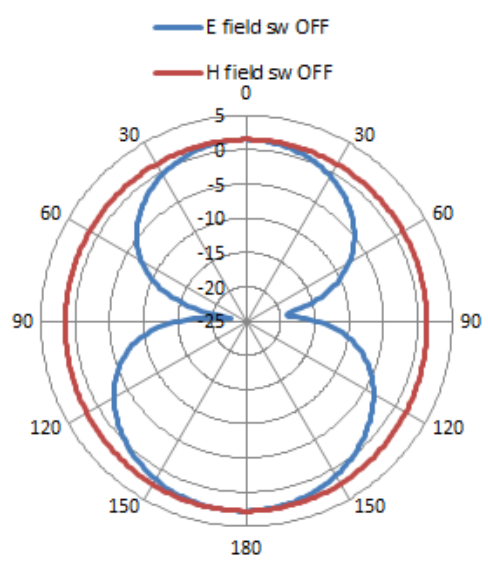

(b)

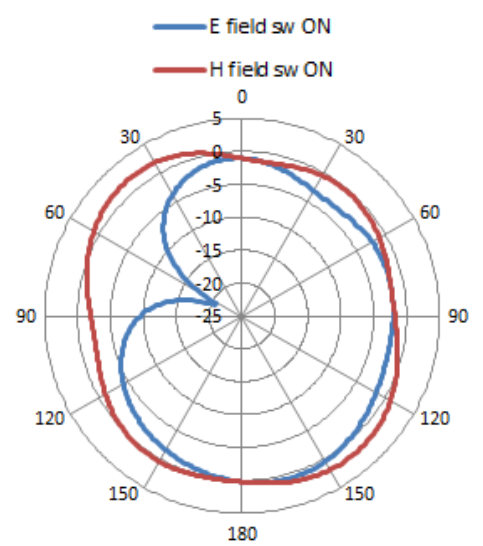

(c)

Fig.4. Directivity of the antenna in the $E$ and $H$ planes at (a) $2.45 \mathrm{GHz}$ and (b) $3.5 \mathrm{GHz}$ (c) $5.2 \mathrm{GHz}$ 


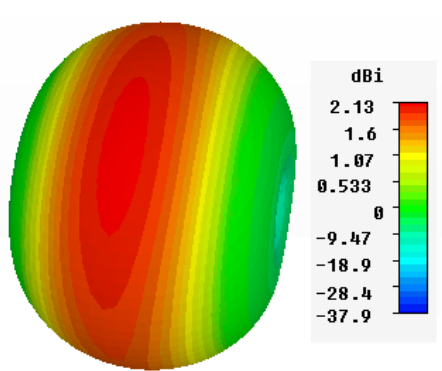

(a)

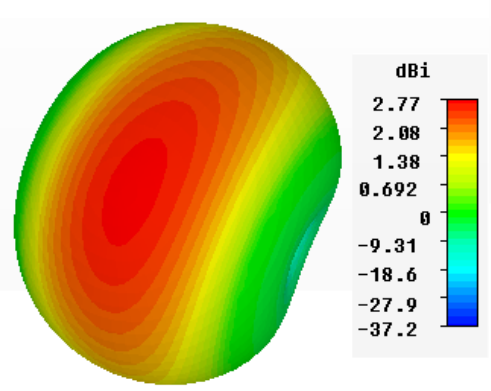

(b)

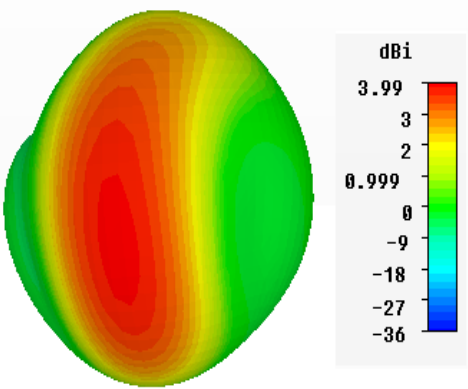

(c)

Fig.5. 3D Far field directivity pattern (a) $2.45 \mathrm{GHz}$ (c) $3.5 \mathrm{GHz}$ (c) $5.2 \mathrm{GHz}$

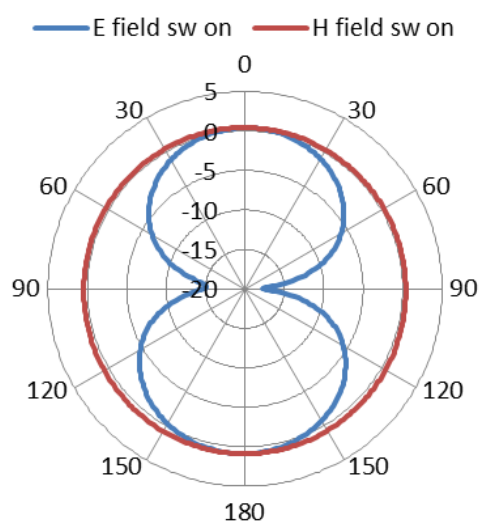

(a)

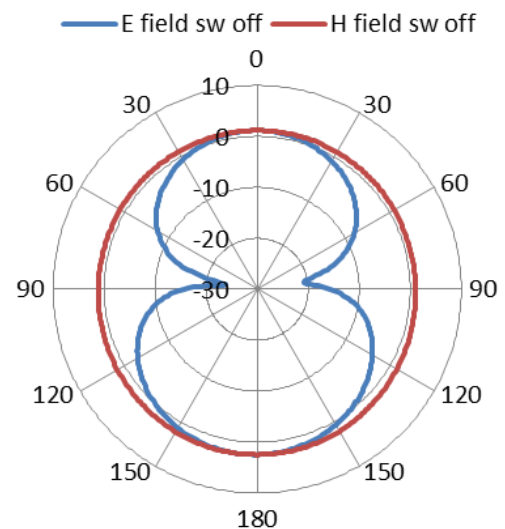

(b)

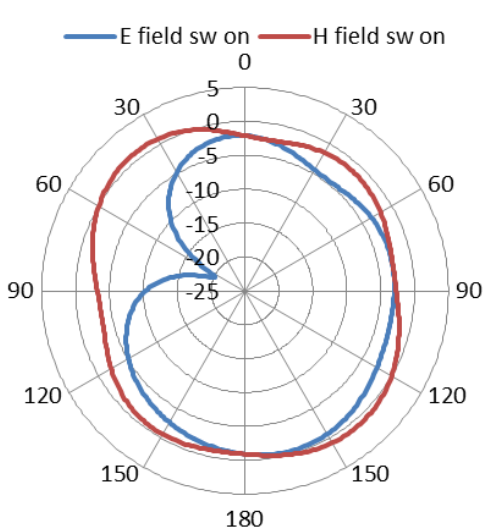

(c)

Fig.6. Gain of the antenna in the $E$ and $H$ planes at (a) $2.45 \mathrm{GHz}$ and (b) $3.5 \mathrm{GHz}$ (c) $5.2 \mathrm{GHz}$

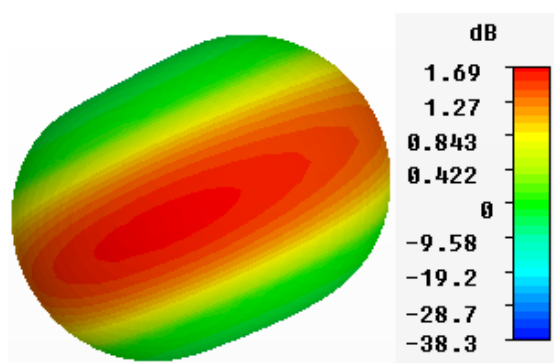

(a)

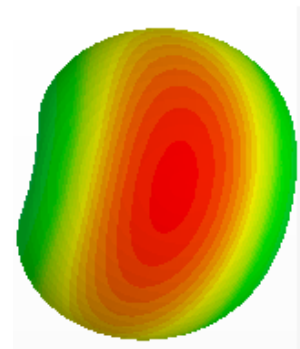

(b)
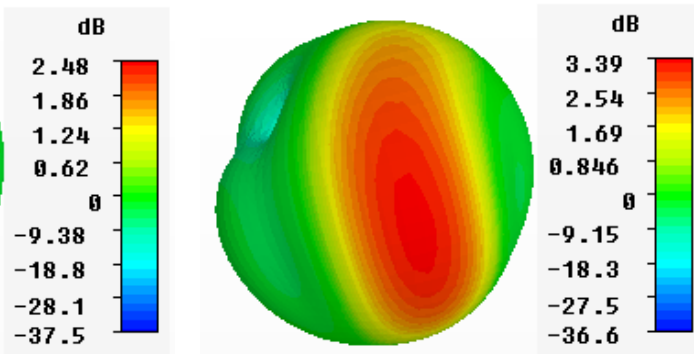

(c)

Fig.7. 3D Far field gain pattern (a) $2.45 \mathrm{GHz}$ (c) $3.5 \mathrm{GHz}$ (c ) $5.2 \mathrm{GHz}$

Table 3. Summarized simulated results

\begin{tabular}{llll}
\hline Parameters & \multicolumn{2}{l}{ SW ON } & SW OFF \\
\hline Frequencies(GHz) & 2.45 & 5.2 & 3.5 \\
Gain(dB) & 1.48 & 2.47 & 3.26 \\
Return Loss (dB) & -15 & -13.55 & -27.1 \\
Bandwidth (\%) & 13.5 & 9.94 & 35.72 \\
Directivity(dBi) & 2.13 & 2.27 & 3.99 \\
VSWR & 1.48 & 1.09 & 1.49 \\
Efficiency (\%) & 86 & 92.5 & 84.6 \\
\hline
\end{tabular}


To observe resonant lengths, surface electric fields (E field) recorded at the frequencies of interest (i.e. 2.45, 3.45, 5.2 $\mathrm{GHz})$ are illustrated in Fig. 8. The entire length of the 9-shape patch radiates at lowest $(2.4 \mathrm{GHz})$ frequency. The vertical arm of the patch up to the switch position, mainly contributes in radiating at $3.5 \mathrm{GHz}$. It is worth noticing that the upper loop in the 9-shape patch is primly responsible for radiation at the highest frequency band $(5.2 \mathrm{GHz})$. The effective resonant lengths are encircled in Fig. 8.

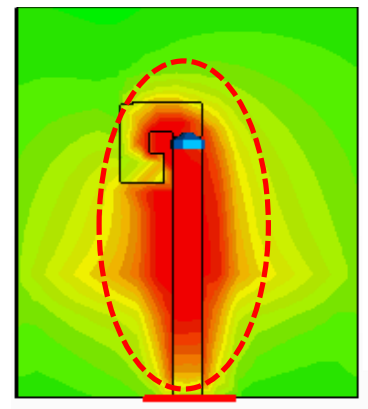

(a)

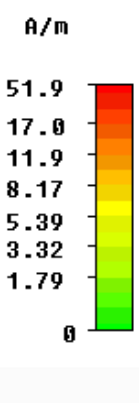

1

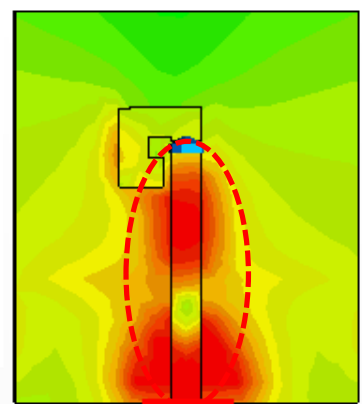

(b)
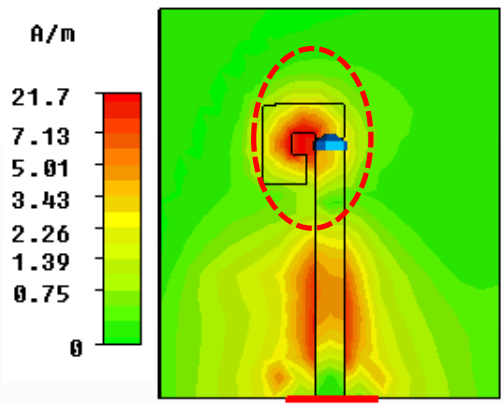

(c)

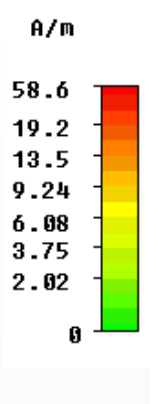

Fig.8. Electric Field Surface Plots at (a) $2.45 \mathrm{GHz}$ (b) $3.5 \mathrm{GHz}$ (c) $5.2 \mathrm{GHz}$

\section{Conclusions}

In this paper a novel 9-shaped frequency reconfigurable planer monopole antenna for Wi-Fi ( $2.45 \mathrm{GHz})$, Wi-MAX (3.5 $\mathrm{GHz})$ and WLAN $(5.2 \mathrm{GHz})$ has been presented to support multi band operations. The re-configurability has been achieved by changing the state of switch (lumped element). The designed antenna performed in single band mode (Wi-MAX at 3.5 $\mathrm{GHz}$ ) when the switch was in the OFF state, while the same antenna worked in dual band mode (Wi-Fi at $2.45 \mathrm{GHz}$ and WLAN at $5.2 \mathrm{GHz}$ ) when the switch was turned ON The designed antenna is of compact size, light weight highly efficient (84-92 \%), and can be used in Wi-Fi, Wi-MAX and WLAN based wireless applications in modern communication devices like laptops, smart phones and other portable devices. A prototype of the proposed antenna will be fabricated to validate the numerical results. The directivity and gain can be further enhanced by using a multi-band electrometric bandgap (EBG) structure as a ground plane.

\section{Acknowledgements}

The authors of this manuscript thankfully acknowledge, CST MWS for the simulation tool for conducting the numerical analysis of the proposed antenna. We are also grateful to the Higher Education Commission of Pakistan for supporting this research.

\section{References}

[1] Ramadan, A., M. Al-Husseini, K. Y. Kabalan and A. EI-Hajj. Fractal-shaped reconfigurable antennas. INTECH Open Access Publisher, 2011; 1: 237-250.

[2] L. N. Pringle, P. H. Harms and S. P. Blalock. A reconfigurable aperture antenna based on switched links between electrically small metallic patches. IEEE Transactions on Antennas and Propagation, 2004, 52: 1434-144.

[3] Picasso: Flexible RF and Spectrum Slicing, http://steven-hong.com/Picasso.html, Accessed on 30 January 2016.

[4] M. R. Hamid, P. Gardner, P. S. Hall and F. Ghanem. Switched-band Vivaldi antenna. IEEE Transactions on Antennas and Propagation, 2011, 59:1472-1480.

[5] C. Wang, Z. H. Yan, P. Xu, J. B. Jiang and B. Li. Trident-shaped dual-band CPW-fed monopole antenna for PCS/WLAN applications. Electronics letters, 2011, 47:231-232.

[6] G. L. Xin and J. P. Xu. Wideband miniature G-shaped antenna for dual-band WLAN applications. Electronics Letters, 2007, 43: 1330-1332.

[7] H. F. AbuTarboush, R. Nilavalan, K. M. Nasar and H. S. Al-Raweshidy, D. Budimir. A reconfigurable H-shape antenna for wireless applications. IEEE Conference on Antennas and Propagation (EuCAP), 2010, 1-4.

[8] S. A. A. Shah, M. F. Khan, S. Ullah, and J. A. Flint. Design of a multi-band frequency reconfigurable planar monopole antenna using truncated ground plane for Wi-Fi, WLAN and WiMAX applications. IEEE International Conference on Open Source Systems and Technologies (ICOSST), 2014, 151-155. 
[9] Z. Cui, Y. C. Jiao, L. Zhang and F. S. Zhang. The band - notch function for a printed ultra - wideband monopole antenna with E - shaped slot. Microwave and Optical Technology Letters, 2008, 50 (8): 2048-2052.

[10] W. C. Liu and C. F. Hsu. Dual-band CPW-fed Y-shaped monopole antenna for PCS/WLAN application. Electronics Letters, vol. 41, no. 7, pp. 390-391, March. 2005.

[11] S. L. S. Yang, A. Kishk, and K. F. Lee. Frequency reconfigurable U-slot microstrip patch antenna. IEEE Antennas and Wireless Propagation Letters, 2008, 7: 127-129.

[12] S. V. Shynu., G. Augustin, C. K. Aadannan,.p. Mohanan. C-shaped slot loaded reconfigurable microstrip antenna. Electronics Letters, 2006, 42(6): 316-318.

[13] M. I. Lai, T. Y. Wu, J. C. Hsieh, C. H. Wang and S. K. Jeng. Design of reconfigurable antennas based on an L-shaped slot and PIN diodes for compact wireless devices. IET Microwaves, Antennas \& Propagation, 2009, 3(1): 47-54.

[14] Y. L. Kuo, K. L. Wong. Printed double-T monopole antenna for 2.4/5.2 GHz dual-band WLAN operations. IEEE Transactions on Antennas and Propagation, 2003, 51(9): 2187-2192.

[15] J. R. Panda, R. S. Kshetrimayum. A printed F-shaped dual-band monopole antenna for RFID and WLAN applications. IEEE International Conference on Computer and Communication Technology (ICCCT), 2010, 789-791.

[16] Hayat Errifi, Abdennaceur Baghdad, Abdelmajid Badri, Aicha Sahel. "Radiation Characteristics Enhancement of Microstrip Triangular Patch Antenna using Several Array Structures." International Journal of Wireless and Microwave Technologies(IJWMT), Vol. 5, No. 3, pp. 1-17, May 2015. DOI: 10.5815/ijwmt.2015.03.01.

[17] Ali A. Saleh, Abdulkareem S. Abdullah. A Novel Design of Patch Antenna Loaded with Complementary Split-Ring Resonator and L- Shape Slot for (WiMAX/WLAN) Applications. International Journal of Wireless and Microwave Technologies(IJWMT), Vol. 4, No. 3, pp. 16-25, October 2014. DOI: 10.5815/ijwmt.2014.03.02.

[18] Idris IH, Hamid MR, Jamaluddin MH, Rahim MK, Kelly JR, Majid HA. Single-, Dual-and Triple-band Frequency Reconfigurable Antenna. Radioengineering. 2014; 23(3).

[19] C. A. Balanis. Antenna Theory, Analysis and Design. $2^{\text {nd }}$ Ed., J. Wiley \& Sons, New York, USA, 1997.

[20] Hirtenfelder F. Effective antenna simulations using CST MICROWAVE STUDIO®. In 2nd IEEE International ITG Conference on Antennas, 2007. INICA'07. 2007, 239-239.

\section{Authors' Profiles}

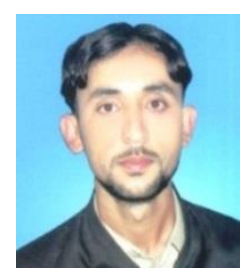

Izaz Ali Shah is a research student in the Department of Telecommunication Engineering, UET Peshawar. His research interests are reconfigurable antennas, patch antennas and wearable antennas.

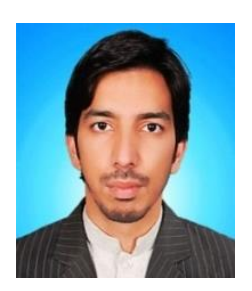

Shahzeb Hayat is a research student in the Department of Telecommunication Engineering, UET Peshawar. His current research interests include planar and reconfigurable patch antennas, and specific absorption rate analysis of wearable antennas.

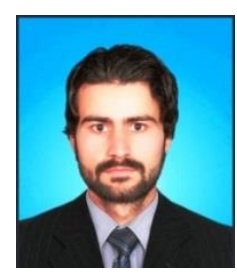

Ihtesham Khan is a research student in the Department of Telecommunication Engineering, UET Peshawar. He is working on reconfigurable patch antennas and electromagnetic bandgap structures. 


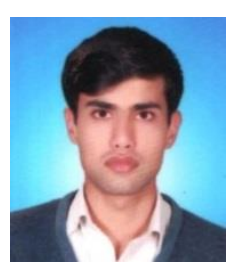

Imtiaz Alam is a research student in Telecommunication Engineering, Department, UET Peshawar. He works on patch antennas and electromagnetic metamaterials.

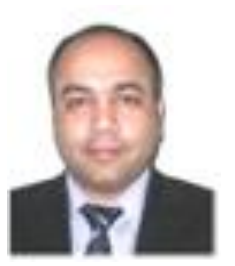

Sadiq Ullah is Assistant Professor at the Department of Telecommunication Engineering, University of Engineering \& Technology, Peshawar, Pakistan. Sadiq Ullah received B.Sc. Electrical Engineering from University of Engineering and Technology, Peshawar, Pakistan. He achieved his M.Sc. in Electrical Engineering from University of Engineering and Technology Taxila, Pakistan. In 2007, he joined the Department of Electronic and Electrical Engineering, at Loughborough University, U.K., and was awarded Ph.D. for his research in the field of design and measurement of metamaterial based antennas in 2010. He worked as an Assistant Manager (Electronics) in a public sector R and D organization in Islamabad, where his main responsibilities were hardware, software co-design, designing and testing of high precession electronics, test equipment. His research mainly focuses on design and measurement of low-profile antennas on electromagnetic Bandgap structures. He has been worked as a Research Associate at Loughborough University, where he researched on the propagation effects of rain, snow, ice, fog and forest in millimeter wave band. During his Ph.D., he published his research in international conferences and journals.

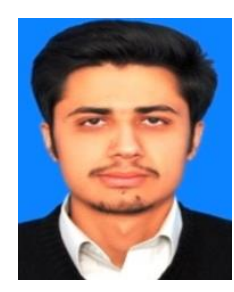

Adeel Afridi is a research student in Koc University, İstanbul with expertise in Electronic Engineering, Communication Engineering, antenna design, optical antennas and metamaterials.

How to cite this paper: Izaz Ali Shah, Shahzeb Hayat, Ihtesham Khan, Imtiaz. Alam, Sadiq Ullah, Adeel Afridi,"A Compact, Tri-Band and 9-Shape Reconfigurable Antenna for WiFi, WiMAX and WLAN Applications",International Journal of Wireless and Microwave Technologies(IJWMT), Vol.6, No.5, pp.45-53, 2016.DOI: 10.5815/ijwmt.2016.05.05 